\title{
HYDROTHERMAL CARBONS FROM HEMICELLULOSE- DERIVED AQUEOUS HYDROLYSIS PRODUCTS AS ELECTRODE MATERIALS FOR SUPERCAPACITORS
}

\author{
Camillo Falco, ${ }^{\text {a-b* }}$ J. M. Sieben, ${ }^{\text {c }}$ N. Brun, ${ }^{\text {b }}$ M. Sevilla, ${ }^{\text {d }}$ Tornbyorn van der Mauelen, ${ }^{e}$ \\ E. Morallón, ${ }^{\mathrm{c}}$ D. Cazorla-Amorós, ${ }^{\mathrm{f}}{ }^{\text {Maria-Magdalena Titirici }}{ }^{\mathrm{b}}$ \\ *camillo.falco@iass-potsdam.de
}

${ }^{a}$ IASS - Institute for Advanced Sustainability Studies, BerlinerStrasse 130, 14467, Potsdam Germany

${ }^{\mathrm{b}}$ Colloid Chemistry, Max-Planck Institute for Colloids and Interfaces, Am Muhlenberg 1, 14476, Potsdam, Germany

${ }^{c}$ Departamento de Química Física and Instituto Universitario de Materiales, Universidad de Alicante, Ap. 99 Alicante, Spain

${ }^{\mathrm{d}}$ Instituto Nacional del Carbón (CSIC), P.O. Box 73, 33080 Oviedo, Spain

${ }^{\text {e }}$ SEKAB E-Technology, PO Box 286, 891 26, Örnsköldsvik (Sweden)

${ }^{\mathrm{f}}$ Departamento de Química Inorgánica and Instituto Universitario de Materiales, Universidad de Alicante, Ap. 99. Alicante, Spain 


\begin{abstract}
Acid pretreatment of lignocellulosic biomass, required for bioethanol production, generates large amounts of by-products, such as the lignin and the hydrolysed hemicellulose fractions, which have found so far very limited applications. In this work we demonstrate how the recovered hemicellulose hydrolysis products can be effectively utilized as a precursor for the synthesis of functional carbon materials via hydrothermal carbonization (HTC). The morphology and chemical structure of the synthesised HTC carbons are thoroughly characterised to highlight their similarities with glucose-derived HTC carbons. Furthermore, two routes for introducing porosity within the HTC carbon structure are presented: i) silica nanoparticle hard-templating, which is shown to be a viable method for the synthesis of carbonaceous hollow spheres, and ii) $\mathrm{KOH}$ chemical activation. The synthesized activated carbons (ACs) show an extremely high porosity (pore volume $\approx 1.0 \mathrm{~cm}^{3} / \mathrm{g}$ ) mostly composed of micropores (90\% of total pore volume). Because of their favourable textural properties, the ACs are further tested as electrodes for supercapacitors, yielding very promising results $\left(300 \mathrm{~F} / \mathrm{g}\right.$ at $\left.250 \mathrm{~mA} \mathrm{~g}{ }^{-1}\right)$ and confirming the high suitability of $\mathrm{KOH}$ activated HTC carbons derived from spruce and corn cobs hydrolysis products as materials for EDLC supercapacitors.
\end{abstract}




\section{Introduction}

The progressive depletion of fossil fuel resources and the need for carbon neutral alternatives are increasingly fostering the research on biofuels. First generation biofuels have been deemed an unfeasible long-term solution, since they are in competition with the food supply chain. On the other hand, lignocellulosic biomass-derived biofuels bypass such a problem. For this reason, in the recent past they have been subject of intense investigations, which have led to several positive developments towards their large-scale utilization. ${ }^{[1-6]}$

Ethanol production through cellulose-derived glucose microbial fermentation is certainly one of the most investigated biofuel synthesis routes. This biological conversion process requires as a first step either enzymatic or acid hydrolysis of the cellulosic substrate into its sugar building units. For this reason, lignocellulosic biomass is typically pretreated, in order to make the cellulose fraction more accessible for the subsequent hydrolysis step. This can be accomplished by various techniques, such as steam explosion, ammonia fibre explosion, concentrated or diluted acid hydrolysis. ${ }^{[7-12]}$

All these methods generate considerable amounts of by-products, such as the isolated lignin fraction and hemicellulose-derived aqueous hydrolysis products. Together, these can account approximately for half of the starting feedstock mass depending on the kind of biomass being utilized. Despite their abundance, these by-products have so far found very limited use, ${ }^{[13-18]}$ as there are far less research efforts focusing on finding new possibilities for effective exploitation than on aiming at the development of new synthesis routes for cellulose-derived biofuels or on increasing the efficiency of existing biofuels. However, the effective utilization of these by-products is potentially crucial to the efficiency enhancement of the overall biomass conversion process to value-added products and to the development of fully sustainable biorefinery schemes. For this reason, the aim of this study is to investigate the use of hemicellulose-derived aqueous hydrolysis products as potential carbon precursors for the hydrothermal carbonisation (HTC) process aimed at the production of high-value functional carbon materials for energy storage applications (e.g. supercapacitors). The hemicellulose-derived by-products were generated during the dilute-acid pretreatment of lignocellulosic biomass (corn cobs, 
spruce) in the cellulosic ethanol demonstration plant in Örnsköldsvik run by SEKAB (Sweden).

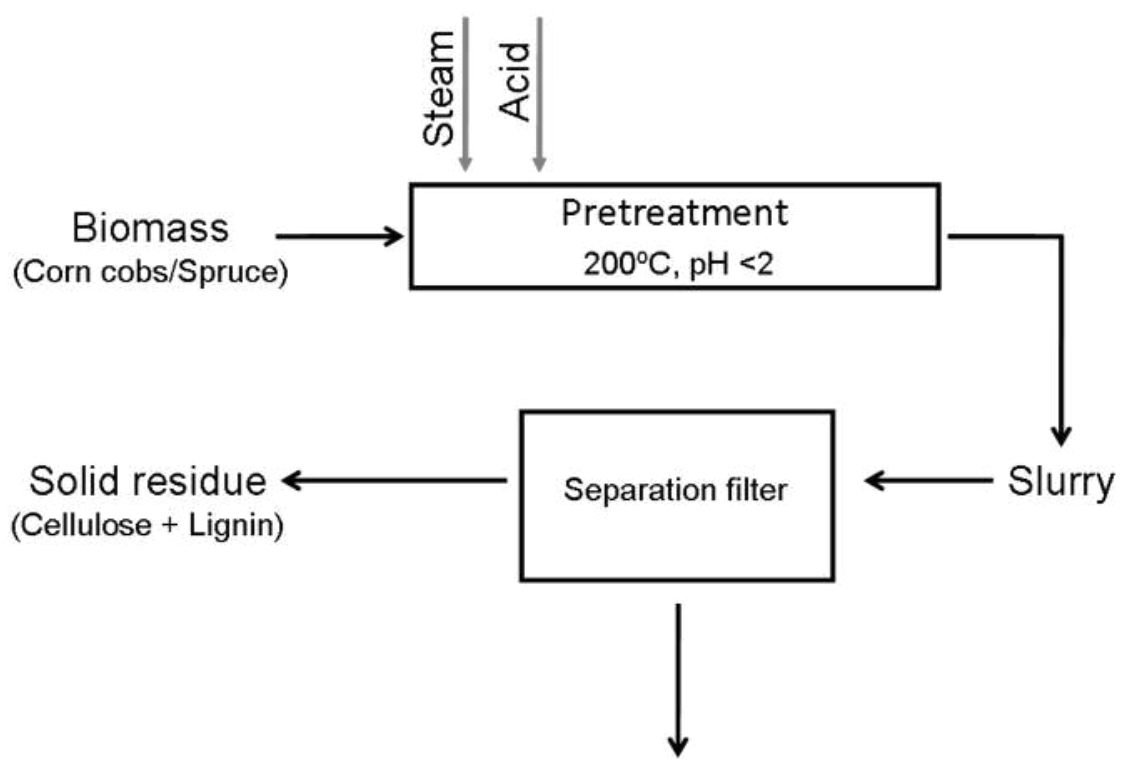

Hydrolysis Products

Figure 1: Flow diagram of the diluted acid pretreatment unit at the cellulosic ethanol demonstration plant in Örnsköldsvik, Sweden

During the pre-treatment step, the lignocellulosic biomass is impregnated with a diluted acid solution and heated by steam (Fig. 1). At these processing conditions (i.e. high temperature, low $\mathrm{pH}$ ), hemicellulose is readily hydrolysed to monomeric carbohydrates. Exiting the reactor, the biomass-containing aqueous stream undergoes a rapid change of pressure leading to further disruption of the biomass fibrous structure and to the formation of a slurry-like effluent, which is then filtered to separate the solids (lignin and cellulose) from the aqueous phase. The latter contains predominantly carbohydrates originating from the biomass hemicellulose fraction. Depending on the employed biomass, the filtrate composition may be characterized by slight variations (Table 1). Currently the main use of this by-product involves its fermentation to ethanol in order to increase the overall process yield. However, this process poses several challenges due to the fact that pentose sugars fermentation requires a modified culture of yeast, whose effectiveness can be very easily inhibited by other components present within the aqueous mixture (e.g. furfural, 5-hydroxymethylfurfural). ${ }^{[19-21]}$ 
Table 1: Composition of the hemicellulose derived aqueous hydrolysis products obtained from diluted acid pretreatment of corncobs and spruce

\begin{tabular}{ccc}
\hline Component & Corn Cobs Hydrolysis Product & Spruce Hydrolysis Product \\
\hline Glucose & $6.8 \mathrm{~g} / 1$ & $18.9 \mathrm{~g} / 1$ \\
Mannose & $2.7 \mathrm{~g} / 1$ & $24.0 \mathrm{~g} / 1$ \\
Galactose & $2.0 \mathrm{~g} / 1$ & $5.0 \mathrm{~g} / 1$ \\
Xylose & $38.2 \mathrm{~g} / 1$ & $10.8 \mathrm{~g} / 1$ \\
Arabinose & $5.1 \mathrm{~g} / 1$ & $3.9 \mathrm{~g} / 1$ \\
Acetic acid & $4.7 \mathrm{~g} / 1$ & $4.9 \mathrm{~g} / 1$ \\
$5-\mathrm{HMF}$ & $0.5 \mathrm{~g} / 1$ & $3.4 \mathrm{~g} / 1$ \\
Furfural & $1.6 \mathrm{~g} / 1$ & $2.6 \mathrm{~g} / 1$ \\
Levulinic acid & $0 \mathrm{~g} / 1$ & $0.3 \mathrm{~g} / 1$ \\
\hline
\end{tabular}

HTC has demonstrated to be an effective synthetic route for the production of functional carbonaceous materials from simple monosaccharides, such as glucose and xylose. ${ }^{[22-27]}$ As these sugars are the main components of the hydrolysis products streams, it is foreseeable that these hemicellulose-derived by-products may be a suitable carbon precursor for the synthesis of high-value carbon-negative functional HTC materials. To confirm the feasibility of this hypothesis, this study compares the carbonaceous materials obtained from the hydrothermal treatment of the hemicellulose-derived hydrolysis products to the one that is obtained from glucose HTC. Furthermore, it also shows the possibility of adopting one-pot synthesis templating strategies (e.g. hard-templating) or post-synthesis processing step (e.g. $\mathrm{KOH}$ chemical activation) to obtain HTC carbon material with improved textural properties (e.g. specific ordered morphology, high surface area; Table 3). Promising preliminary results in relation to the use of the chemically activated HTC carbons as supercapacitors electrode materials are lastly presented, showing the effectiveness of this synthesis strategy in converting a low-value biomass-derived industrial by-product into a functional carbon material with evident energy storage applications.

\section{Results and Discussion}

The first part of this study focuses on the HTC of hydrolysis products derived from the diluted acid pretreatment of spruce and corncobs during ethanol production described above. The question whether such waste by-products are suitable precursors for the synthesis of hydrothermal carbon is addressed by comparing the carbonaceous materials 
obtained from hydrothermal treatment of these two feedstocks with those derived from glucose in terms of morphology and chemical structure. In the second part of this study the produced HTC carbons are chemically activated using $\mathrm{KOH}$ and then tested as electrode materials. Furthermore, a templating approach able to generate well-defined nano-sized hollow carbon spheres with controlled pore walls is also described. Such hollow spheres are promising candidates as electrodes materials in either $\mathrm{Li}^{+}, \mathrm{Na}^{+}$, or even $\mathrm{Li}-\mathrm{S}$ batteries. ${ }^{[28-30]}$

\section{Hemicellulose-derived by-products HTC}

SEM analysis reveals that the morphology of the HTC carbons, obtained from both spruce and corn cobs hydrolysis products, is characterised by interconnected microspheres (Fig. 2a-d). This morphology is characteristic of monosaccharide derived HTC carbons. ${ }^{[31]}$ Hydrothermal carbonisation of pure glucose (Fig 2e-f) yields a carbon composed of micrometer sized spherical particles. However, in this latter case the average sphere diameter is smaller and the particle size distribution narrower. A possible explanation for this observation is that the spruce and corn cobs hydrolysis products contain several different carbohydrates generated from hemicellulose hydrolysis (i.e. mannose, galactose, arabinose, xylose), which, as demonstrated by Titirici et al., affect the final particle size. ${ }^{[31]}$
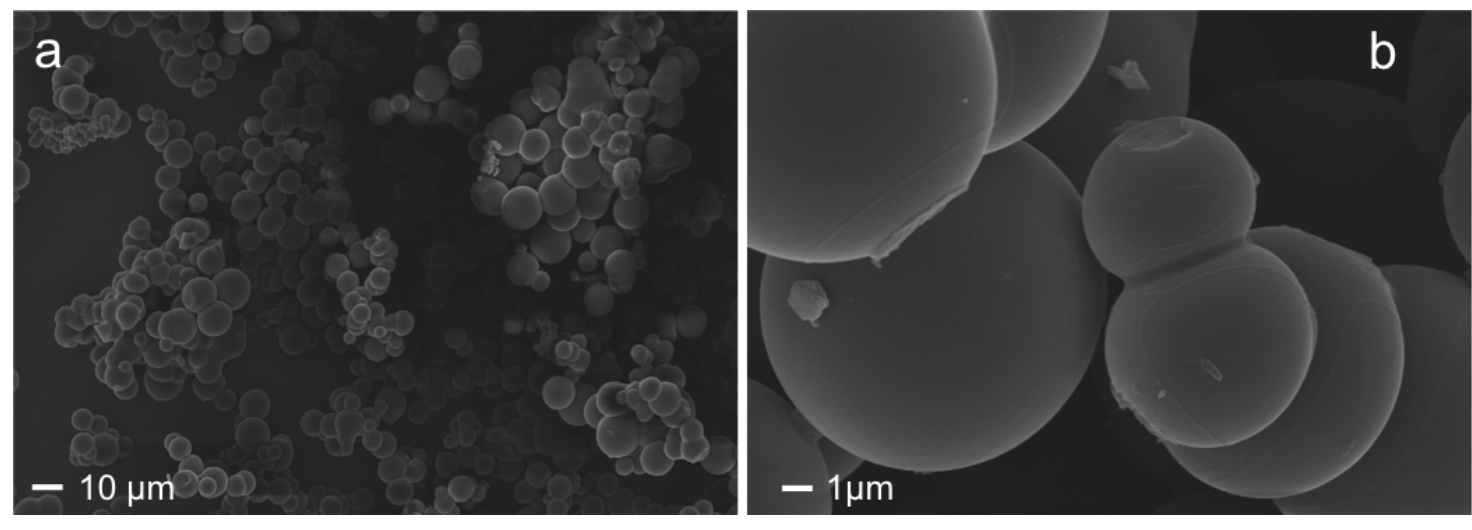


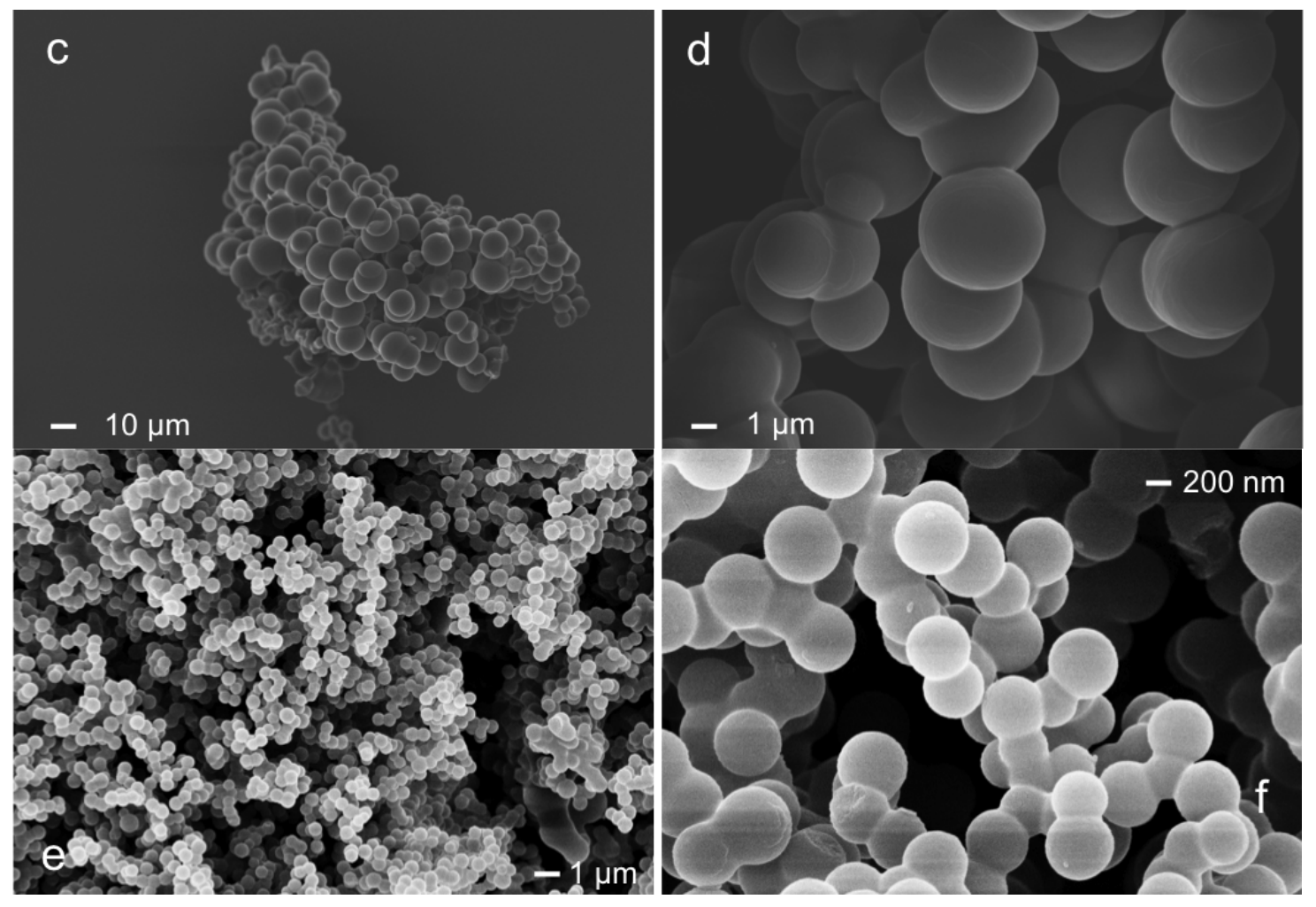

Figure 2: Scanning Electron Micrographs of hydrothermal carbon obtained from spruce hydrolysis product $(\mathrm{a}, \mathrm{b})$, corn cobs hydrolysis product $(\mathrm{c}, \mathrm{d})$ and glucose $(\mathrm{e}, \mathrm{f})$ at $200{ }^{\circ} \mathrm{C}$ and after $24 \mathrm{~h}$.

Elemental analysis (EA) of the HTC carbons synthesised from both, hydrolysis products and pure glucose, shows very similar values (Table 2). This evidence suggests that the HTC of spruce and corncobs hydrolysis products generates a carbonaceous material whose chemical composition and structure can be closely related to the one obtained from pure monosaccharides. Conversely, analysis of HTC yields underlines that this parameter varies considerably depending on the carbon precursor (Table 2). The HTC yields measured for the HTC carbons derived from spruce and corncobs hydrolysis products are higher in comparison to the pure glucose case. This difference is presumably due to the presence of pentose sugars within the lignocellulosic biomasses hydrolysis products (Table 1), which are known to generate HTC carbon via dehydration to furfural.;Error! Marcador no definido. Contrarily, 5-hydroxymethylfurfural (5-HMF) is produced when glucose or generally hexoses are treated under hydrothermal conditions. ${ }^{[32]}$ This latter reaction intermediate has a pronounced tendency to form degradation products (e.g. levulinic acid, formic acid and dehydroxyacetone), especially 
under acidic conditions. ${ }^{[33-34]}$ A higher extent of degradation product formation for hexose sugars might be the cause of lower HTC yields. Further evidence for such a hypothesis is that the highest recorded yield corresponds to the HTC carbon obtained from the corncobs hydrolysis products, which is the feedstock with the largest fraction of pentose sugars (Table 1).

Table 2: Elemental composition and HTC yield of hydrothermal carbons obtained from spruce hydrolysis product, corncobs hydrolysis product and glucose at $200{ }^{\circ} \mathrm{C}$ after $24 \mathrm{~h}$.

\begin{tabular}{ccccccc}
\cline { 2 - 5 } HTC Sample & $\mathbf{H}$ & $\mathbf{C}$ & $\mathbf{O}$ & $\mathbf{N}$ & $\mathbf{S}$ & HTC Yield \% \\
\hline $\begin{array}{c}\text { Spruce Hydrolysis } \\
\text { Product }\end{array}$ & 4.54 & 69.03 & 24.98 & 1.19 & 0.26 & 44.44 \\
$\begin{array}{c}\text { Corn Cobs } \\
\text { Hydrolysis Product }\end{array}$ & 4.55 & 70.36 & 23.50 & 1.43 & 0.16 & 51.36 \\
Glucose $200{ }^{\circ} \mathrm{C}$ & 4.68 & 68.98 & 26.27 & 0.02 & 0.05 & 38.75 \\
\hline
\end{tabular}

The ${ }^{13} \mathrm{C}$ solid state NMR spectra of the HTC carbons obtained from all three carbon precursors show overall very similar features in all the NMR regions (Carbonyl groups, Aromatic and Aliphatic), which have been shown to be relevant for the analysis of the chemical structure of hydrothermal carbons (Figure 3). ${ }^{[35-36]}$ This is the evidence that carbonaceous materials obtained from corncob and spruce hydrolysis products have the same chemical structure as the one obtained from glucose. However, some minor differences can still be found in the aromatic region of the spectra with a more focused analysis Firstly, it can be observed that the HTC carbon derived from glucose at $200{ }^{\circ} \mathrm{C}$ already shows a well-developed arene-like aromatic structure: the most prominent peak in the aromatic region is the one at $125-128 \mathrm{ppm}$. This feature can be attributed to the processing temperature, which is high enough $\left(\mathrm{T}>180^{\circ} \mathrm{C}\right)$ for the polyfuranic structure to be partially converted into a more aromatic one. ${ }^{[37]}$ The same fingerprint applies also to the samples obtained from the two hydrolysis products. However, in the two latter cases the relative intensity of the central peak is even higher, especially for the corncob sample. This can be related to the presence of pentose sugars within the starting feedstocks, which 
have been shown to generate hydrothermal carbons with a higher aromatic character than those obtained from hexose sugars. ${ }^{[31]}$

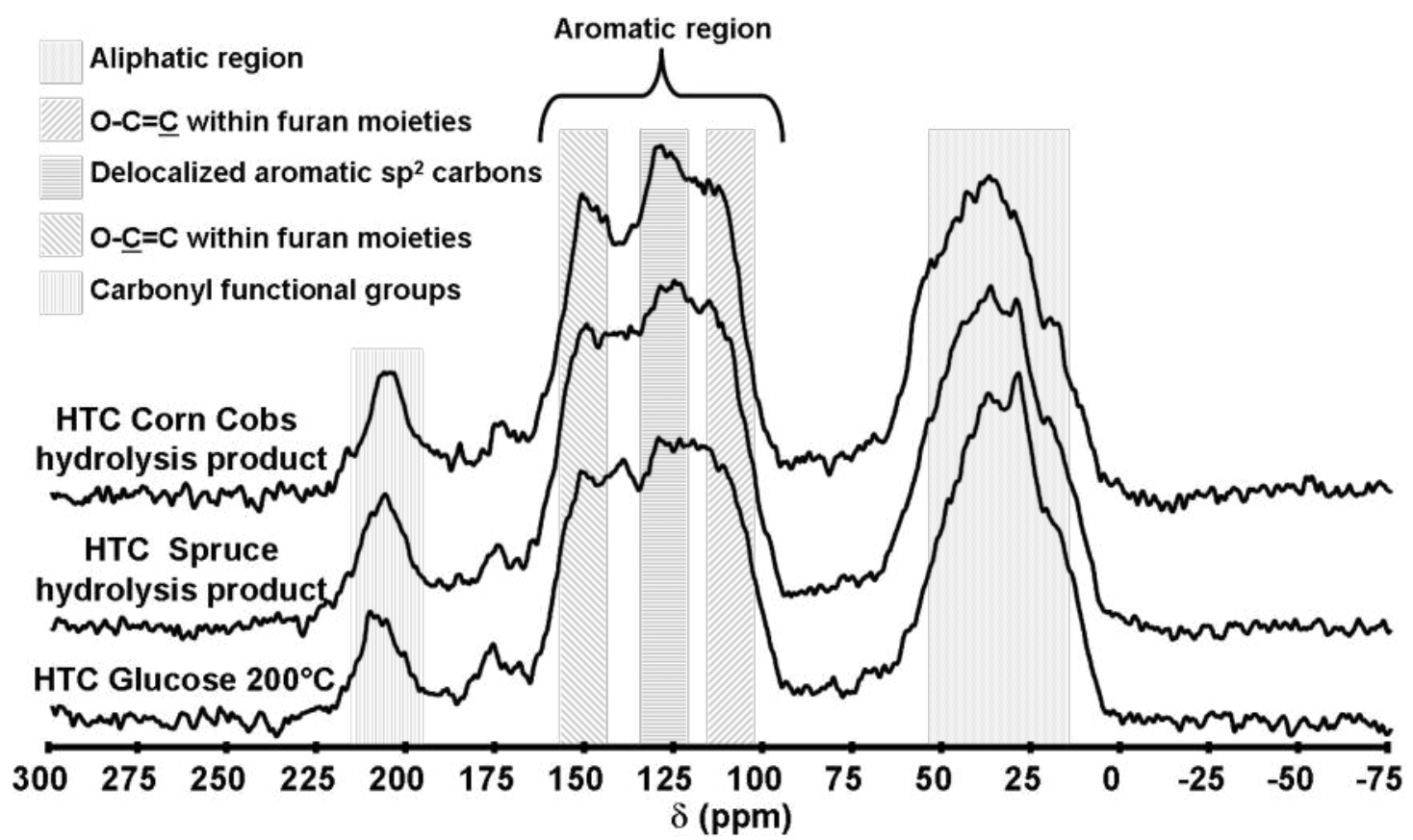

Figure 3: Solid state ${ }^{13} \mathrm{C} C P$ NMR spectra of hydrothermal carbon obtained from glucose, spruce and corn cobs hydrolysis products at $200{ }^{\circ} \mathrm{C}$ and after $24 \mathrm{~h}$.

FTIR analysis of all three hydrothermal carbons confirms the conclusions derived from the analysis of the NMR spectra. All profiles shown in Figure 4 are characterized by the same relevant peaks that highlight the presence the same functional groups within all the obtained samples. However, one main difference can be observed. The ratio of the $v(\mathrm{C}=\mathrm{O})$ to the $v(\mathrm{C}=\mathrm{C})$ peaks is lower for the HTC carbons obtained from the hydrolysis products. A possible explanation might be that the $\mathrm{pH}$ of these two samples solutions is lower due to the presence of $\mathrm{H}_{2} \mathrm{SO}_{4}$ remaining from the pre-treatment stage. Therefore, the acid might enhance the degree of decarbonylation of the obtained HTC carbons, thus reducing the relative intensity of the carbonyl peak. 


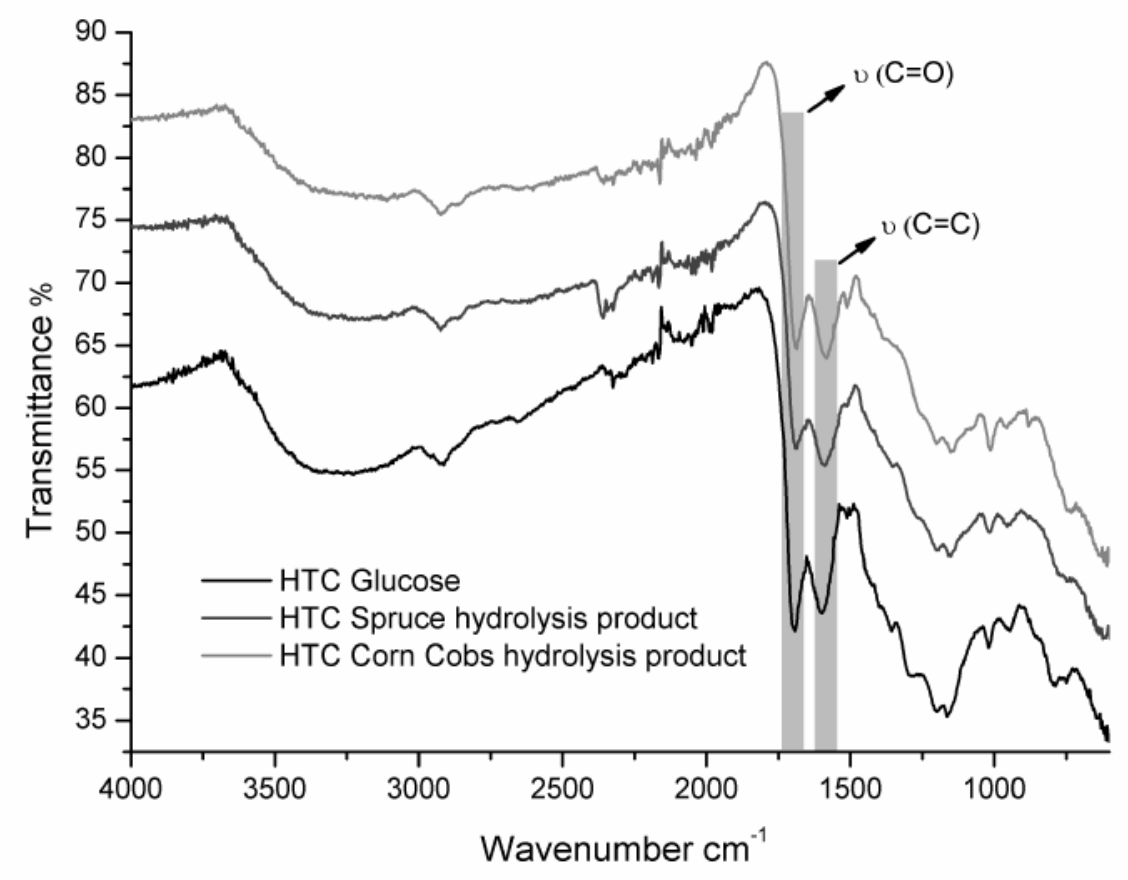

Figure 4: FTIR spectra of hydrothermal carbon obtained from glucose, spruce and corn cobs hydrolysis products at $200{ }^{\circ} \mathrm{C}$ and after $24 \mathrm{~h}$.

\section{Introducing porosity in hydrolysis product derived HTC carbons}

As generally observed for HTC carbons, the hydrolysis products have no relevant porosity, which hinders their potential utilization for energy storage applications. To introduce porosity within their structure, an attempt was made to obtain hollow spheres by templating silica nanoparticles. TEM micrographs of the HTC carbons replicating the silica particles show that the templating strategy represents a viable alternative to produce carbon hollow spheres (Figure 5). Tang et al. have recently demonstrated that HTC carbons, characterized by such morphology, show very promising performances as anode materials for $\mathrm{Na}$ and Li batteries. ${ }^{[28,29]}$ As a consequence, it is possible that the templated hydrolysis-product-derived HTC carbons may be also successfully employed for such an end application. 

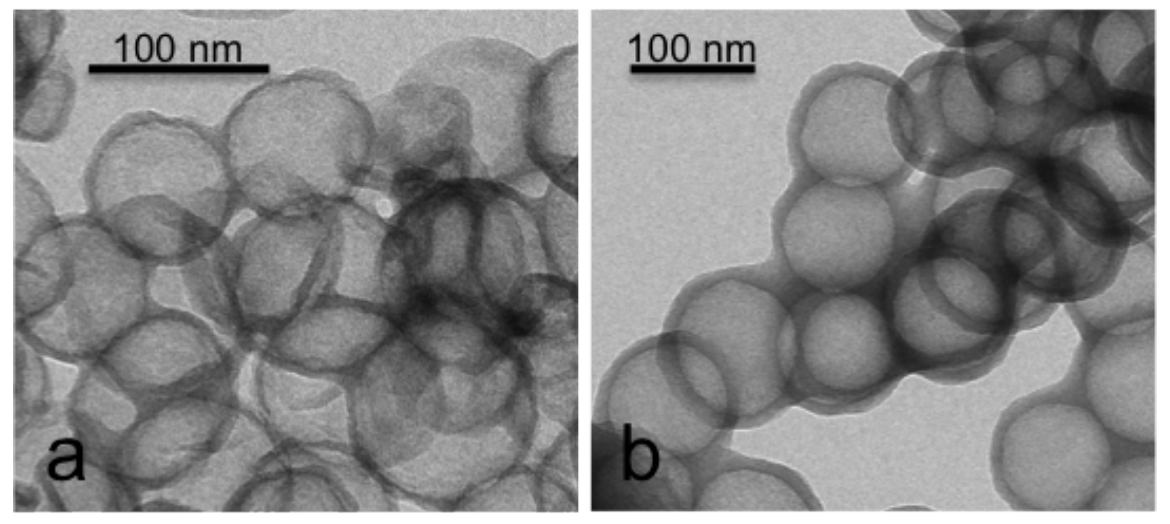

Figure 5: TEM micrographs of hydrolysis products-derived HTC carbons ( $\mathrm{a}$ - spruce, $\mathrm{b}$ - corn cobs) after silica nanoparticles templating.

$\mathrm{KOH}$ chemical activation was employed as a second synthesis strategy to introduce microporosity in hydrolysis-product derived HTC carbons. SEM analysis reveals that the chemical activation process leads to a complete disruption of the morphology observed after HTC (Figure 6). The activated carbon (AC) materials are now composed of macrometer-sized monolithic fragments with sharp edges. Furthermore, higher magnification SEM micrographs show a high level of surface roughness, hinting at the material's extensive microporosity (Figure $6 \mathrm{~b}$ and $\mathrm{d}$ ), which is also confirmed by high resolution SEM micrographs (Figure SI2 in the Supporting Information). This complete morphological rearrangement suggests that the synthesis of ACs presumably proceeds via melt down of the HTC carbon precursor and formation of a liquid-phase intermediate. Such observations are in agreement with the results reported for the chemical activation of carbonaceous precursors with a low degree of crystallinity. ${ }^{[38,39]}$ 

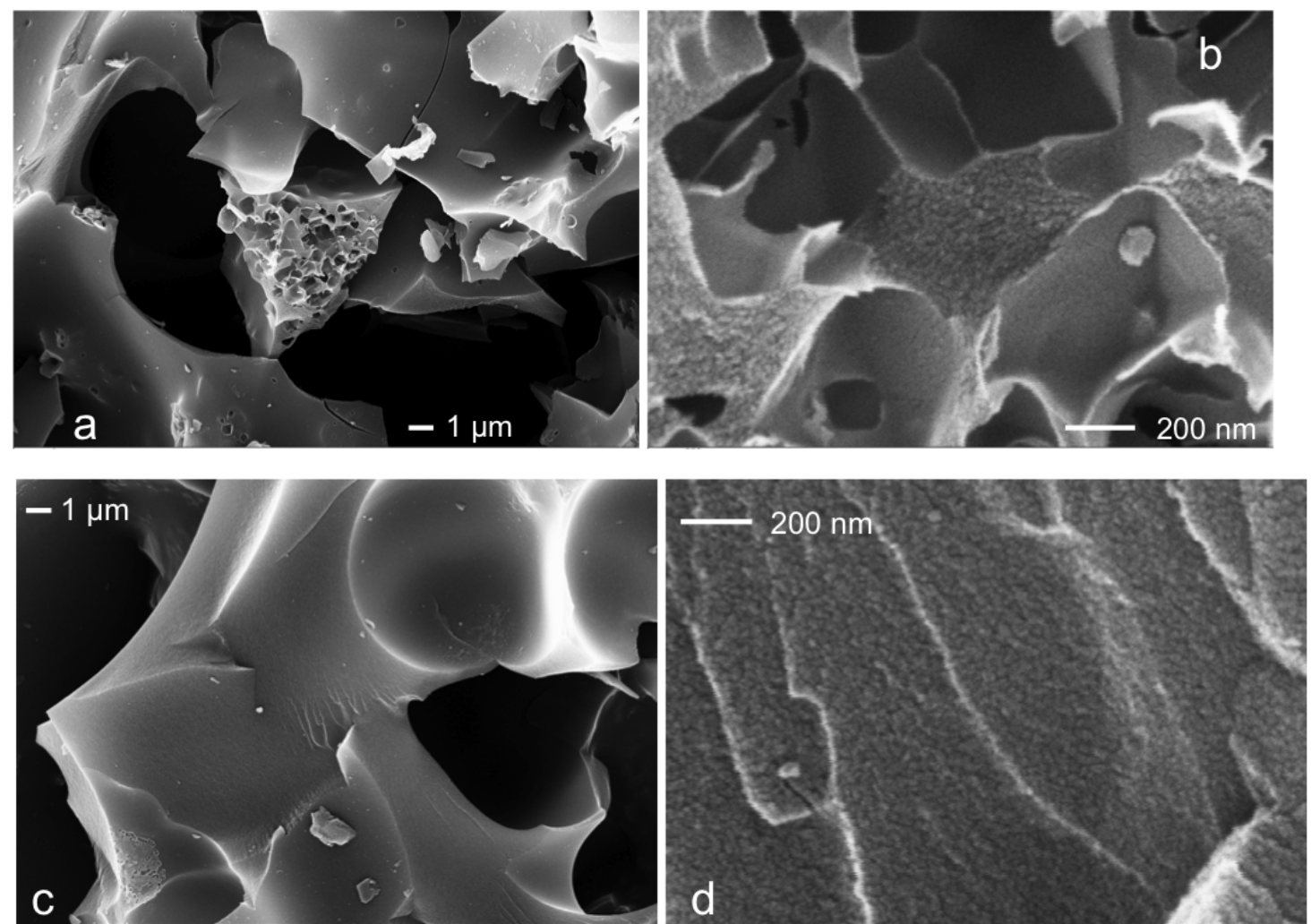

Figure 6: SEM micrographs of HTC carbons derived from hydrolysis products after chemical activation with $\mathrm{KOH}$ : a,b) spruce; c,d) corncobs.

To fully characterize the porosity of the synthesized ACs, both $\mathrm{CO}_{2}$ and $\mathrm{N}_{2}$ gas adsorption were employed. The analysis was performed based on a combination of the Brunauer- Emmett-Teller (BET), and Dubinin-Radushkevich (DR), and DFT models applied to $\mathrm{N}_{2}$ and $\mathrm{CO}_{2}$ adsorption isotherms.

The $\mathrm{N}_{2}$ isotherms of ACs produced from hydrolysis-product derived HTC carbons are characterized by a Type I profile (Figure 7a), exhibiting a sharp adsorption knee at low relative pressures, which is indicative of a narrow pore size distribution (PSD) and the essentially microporous nature of the adsorbents. The high $\mathrm{N}_{2}$ volume uptakes reveal that $\mathrm{KOH}$ activation has effectively led to the development of extensive porosity within the carbon material structure. Such observations are confirmed by the calculated BET surface area and pore volume values (Table 3 ). 

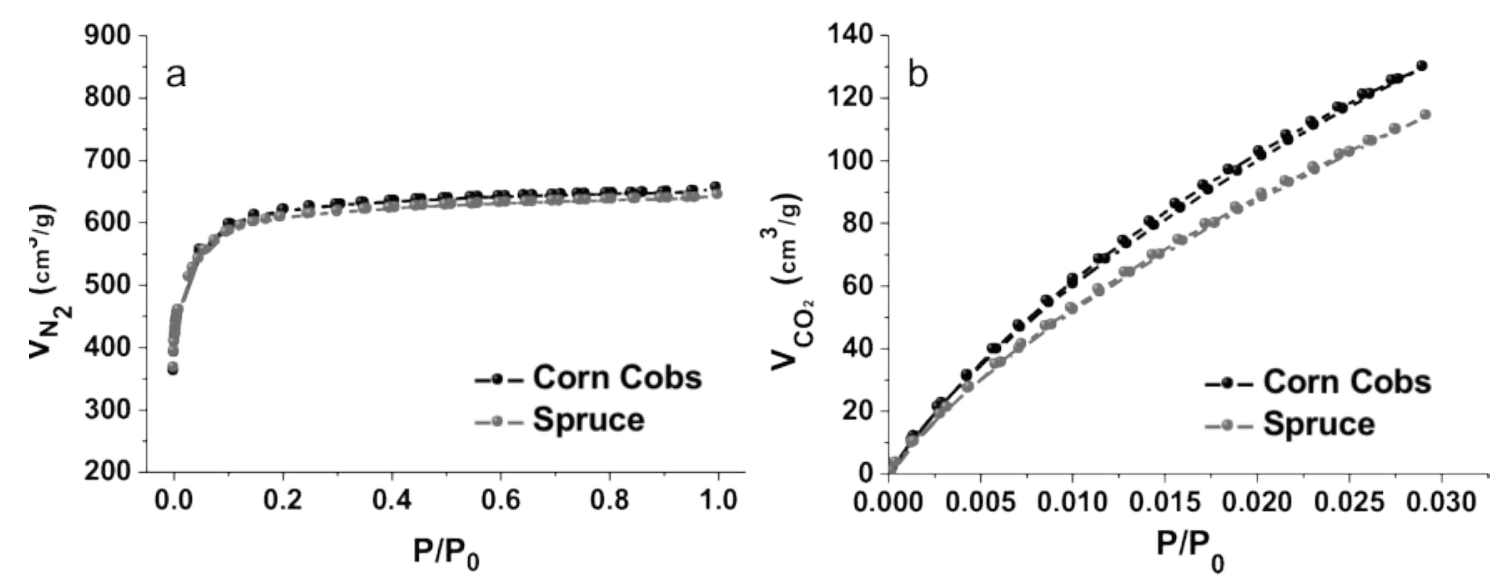

Figure 7: a) $\mathrm{N}_{2}$ and b) $\mathrm{CO}_{2}$ (at $273 \mathrm{~K}$ ) adsorption isotherms of the ACs.

The comparison between the total pore volume and the micropore volume calculated from $\mathrm{N}_{2}$ adsorption confirms that the samples are essentially microporous (Table 3 ). Additionally, the micropore volumes obtained from $\mathrm{CO}_{2}$ adsorption reveal that the samples have a large fraction of narrow micropores ( $\approx 50-60 \%$ of total microporosity) (Fig 7b). The prevalent microporosity of both adsorbents is also confirmed by the PSDs obtained with DFT methods highlighting the absence of relevant mesopore fraction (Fig. $8 \mathrm{a}$ and $\mathrm{b})$.

Table 3: Calculated surface area (S) and pore volume (V) using different models (subscript) on either $\mathrm{N}_{2}$ or $\mathrm{CO}_{2}$ isotherms for the $\mathrm{ACs}$

\begin{tabular}{ccccc}
\hline Sample & $\mathbf{S}_{\text {BET }\left(\mathbf{m}^{2} / \mathbf{g}\right)}$ & $\mathbf{V}_{\mathbf{p}^{\left(\mathrm{cm}^{3} / \mathbf{g}\right)}}{ }^{(\mathbf{a})}$ & $\mathbf{V}_{\mathbf{N 2}-\mathbf{D R}\left(\mathrm{cm}^{3} / \mathbf{g}\right)}$ & $\mathbf{V}_{\mathbf{C O 2 - D R}\left(\mathrm{cm}^{3} / \mathbf{g}\right)}$ \\
\hline Spruce & 2220 & 1.09 & 0.93 & 0.48 \\
Corn Cobs & 2300 & 0.93 & 0.87 & 0.51
\end{tabular}

(a) The total pore volume was determined from the amount of nitrogen adsorbed at $\mathrm{p} / \mathrm{p}_{\mathrm{o}} \sim 0.99$.
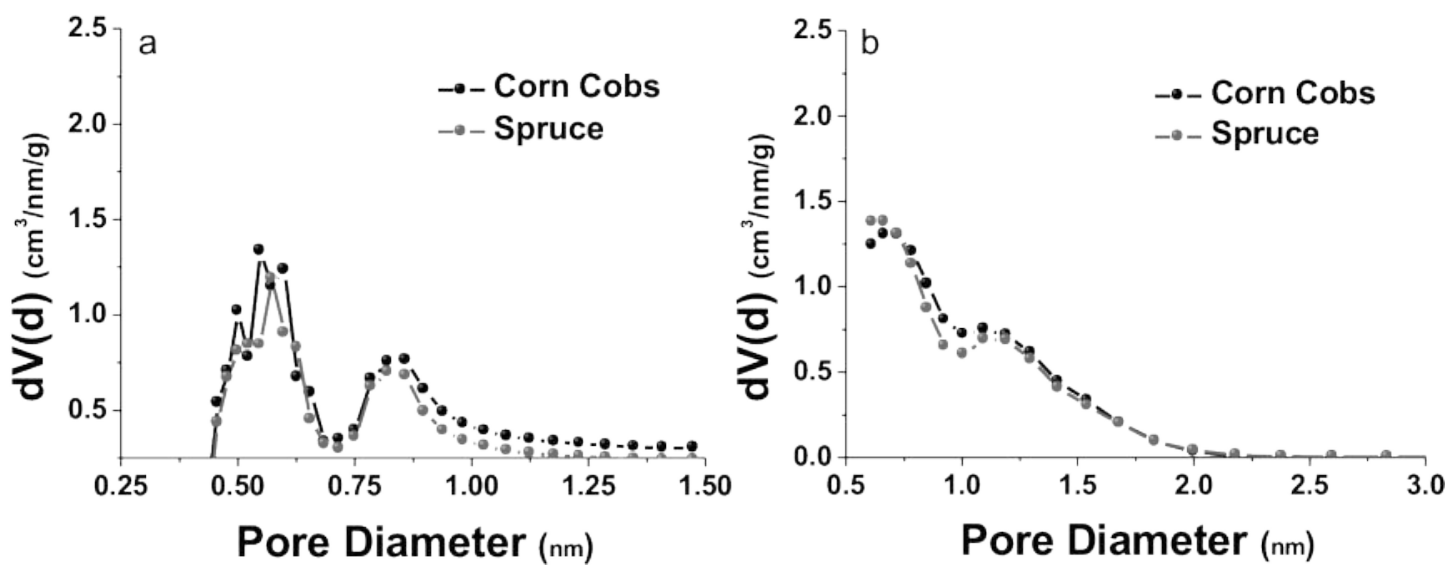
Figure 8: Pore size distributions obtained by applying a) NLDFT method to $\mathrm{CO}_{2}$ isotherms and b) QSDFT method to $\mathrm{N}_{2}$ isotherms.

\section{Electrochemical characterization}

It has been extensively demonstrated that a carbon material for electrochemical capacitors should exhibit good conductivity, high surface area, adequate pore size distribution, excellent corrosion resistance, high thermal stability and presence of electroactive species. ${ }^{[40,41]}$ In this sense, the carbonaceous materials obtained by HTC treatment of biomass are expected to present good electronic conductivity. ${ }^{[42]}$ Furthermore, chemical activation with $\mathrm{KOH}$ allows developing high surface areas and porosity prevalently composed of micropores (Table 3), even maintaining a relatively high content of nitrogen, oxygen and sulphur in the carbon structures (Table SI2 in the Supporting Information).

Fig. 9a shows the cyclic voltammograms of E1 and E2 electrodes (E1: AC from spruce hydrolysis-product-derived HTC carbon; E2: AC from corncob hydrolysisproduct-derived HTC) obtained in a three electrode-cell in acidic medium. Both electrodes exhibit an almost rectangular shape, indicating that the main contribution to capacitance is the process involving the charging and discharging of the double layer. Besides, the voltammetric curve for E2 electrode exhibits some redox processes at around $0.65 \mathrm{~V}$ during the positive sweep and the counter peak at $0.45 \mathrm{~V}$ during the negative sweep, that are associated to surface oxygen groups. The specific capacitance (C) of E1 and E2 measured from the CVs curves is $261\left(11.8 \mu \mathrm{Fcm}^{-2}\right.$ calculated using the BET surface area) and $291 \mathrm{~F} \mathrm{~g}^{-1}\left(12.7 \mu \mathrm{Fcm}^{-2}\right)$, respectively. These values are comparable to those found for other advanced nanocarbon materials. ${ }^{[43]}$

In addition, galvanostatic experiments were used to measure the specific capacitance of both samples (Fig. 9b). The capacitance values were calculated according to equation $j t / \Delta E$, where $j$ is the discharge current density per mass unit, $t$ the discharge time and $\Delta E$ the voltage windows. Interestingly, these experiments show that sample E1 has a higher resistance than sample E2. As both of them have similar porous textures, these differences should be attributed to the different nanocrystalline structure. Fig. 9c shows the variation of the specific capacitance as gravimetric current density increases. It can be 
observed that the capacitance decreases for both carbon materials following a similar trend, the capacitance value of E2 remains higher than E1 within the entire current range (from 25 to $1000 \mathrm{~mA} \mathrm{~g}^{-1}$ ). The gradual loss of capacitance with current density is presumably related to the hindered or restricted diffusion of ions within small pores (ionsieving effect), highlighting that the electrochemical double layer formation within the micropores becomes less complete at progressively higher current densities. ${ }^{[4]}$ The specific capacitances obtained from charge-discharge experiments at $250 \mathrm{~mA} \mathrm{~g}^{-1}$ are in good agreement with those measured from CV experiments. Capacitance values of 267 and $300 \mathrm{~F} \mathrm{~g}^{-1}$ were measured for the electrodes E1 and E2, respectively. As it is expected, the higher the surface area and the heteroatom content of the carbon material, the higher the specific capacitance.

Furthermore, it can be seen that both materials exhibit high values of capacitance in acidic media, which are very promising compared to other activated carbons with similar porosities. $^{[45-47]}$ 

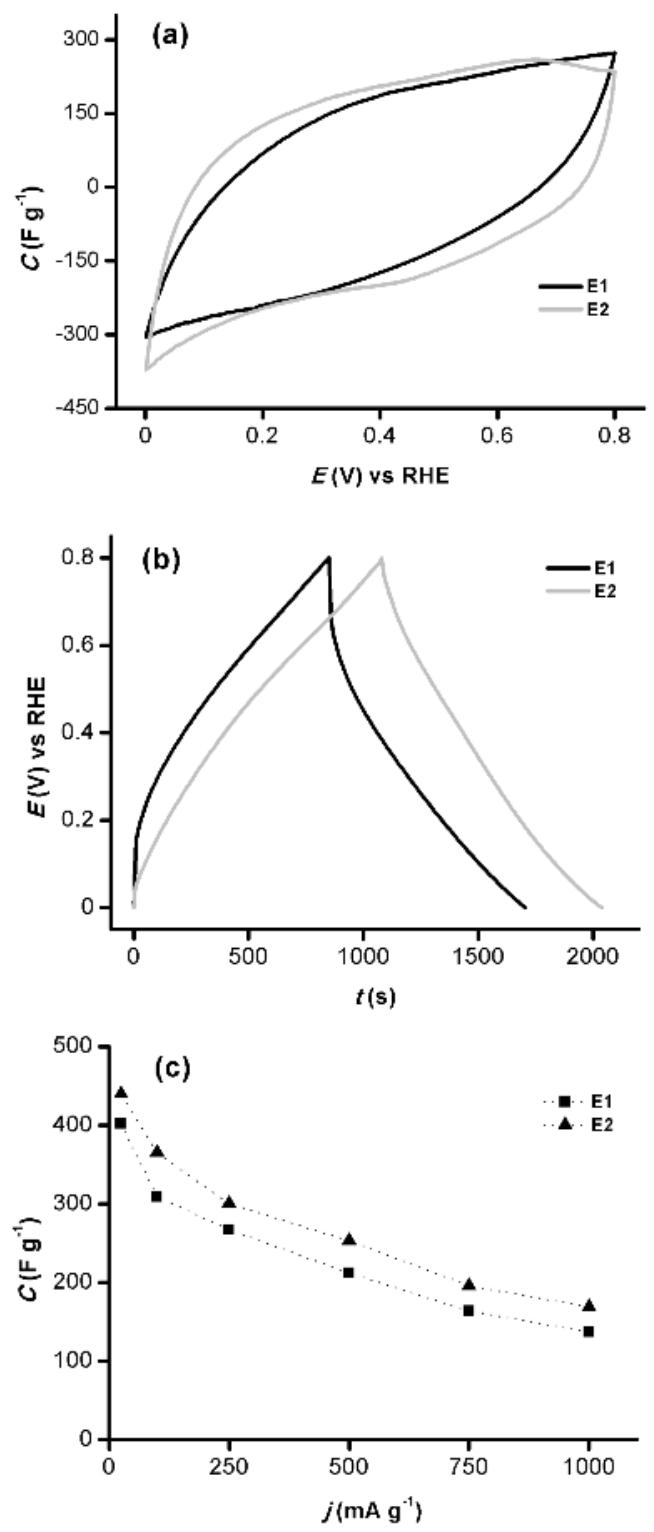

Figure 9: Electrochemical characterization using a three-electrode cell in $0.5 \mathrm{M} \mathrm{H}_{2} \mathrm{SO}_{4}$. Cyclic voltammograms obtained at a scan rate of $1 \mathrm{mV} \mathrm{s}^{-1}$ (a). Galvanostatic curves at a current density of $250 \mathrm{~mA} \mathrm{~g}^{-1}$ (b). Specific capacitance variation with increase of current density (c).

Although a three-electrode characterization is helpful for determining the electrochemical characteristics of a determined material, two-electrode test cell provides the best indication of their performance since reproduces the physical configuration, internal voltages and charge transfer that occurs in a packaged supercapacitor. ${ }^{[48]}$ In this 
respect, two-electrode cells with the same carbon material in both electrodes were assembled to evaluate the performance of the materials as electrodes in supercapacitors. The electrochemical characterization was the same used to evaluate the electrodes in a three-electrode cell. Fig. 10a shows the charge/discharge curves obtained for both symmetric capacitors E1/E1 and E2/E2 at a gravimetric current density of $250 \mathrm{~mA} \mathrm{~g}^{-1}$, while the evolution of the capacitance with $j$ is shown in Figs. 10b, SI4 and SI5. The chronopotentiograms have a quasi linear shape and that the coulombic efficiency is above $99 \%$, which implies that no additional faradic reaction contribute significantly to the charge/discharge process in this voltage window.

In both capacitors the capacitances decrease similarly as the current density increases, and the capacitance of the symmetric E2/E2 capacitor is higher over the whole range of current densities.

In addition, it is important to remark that the specific capacitances determined from $\mathrm{CV}$ experiments at $1 \mathrm{mV}^{-1}$ (Figure SI3) are comparable to the values calculated from galvanostatic charge-discharge profiles at $250 \mathrm{~mA} \mathrm{~g}^{-1}$.

To obtain a complete overview of the performance of the symmetric capacitors, the specific power and energy have been calculated according to the following expressions [Eqs. (1) and (2)]:

$$
\begin{aligned}
E & =\frac{\mathbf{1}}{\mathbf{2}} C V \\
P_{\max } & =\frac{V_{\max }^{2}}{4 E S R m_{T}}
\end{aligned}
$$

where ESR is the equivalent series resistance determined from ohmic drop in the charge/discharge measurements and $m_{\mathrm{T}}$ is the total active mass of the capacitor.

A Ragone plot summarizes the performance of both capacitors in the whole density current region investigated in this work (Fig. 11). For instance, at $250 \mathrm{~mA} \mathrm{~g}^{-1}$ the symmetric capacitors E1/E1 and E2/E2 develop good energy densities, with values of 6.4 and $7 \mathrm{~W} \mathrm{~h} \mathrm{~kg}^{-1}$ respectively and power densities of 0.76 and $1.08 \mathrm{~kW} \mathrm{~kg}^{-1}$ in the studied voltage window. These values confirm that the activated HTC carbons derived from spruce and corncob biomass are promising materials for electrical double layer 
supercapacitors (EDLCs), the performance of which could be further improved by tailoring the AC properties (e.g. , PSD, heteroatom content) during the synthesis step.
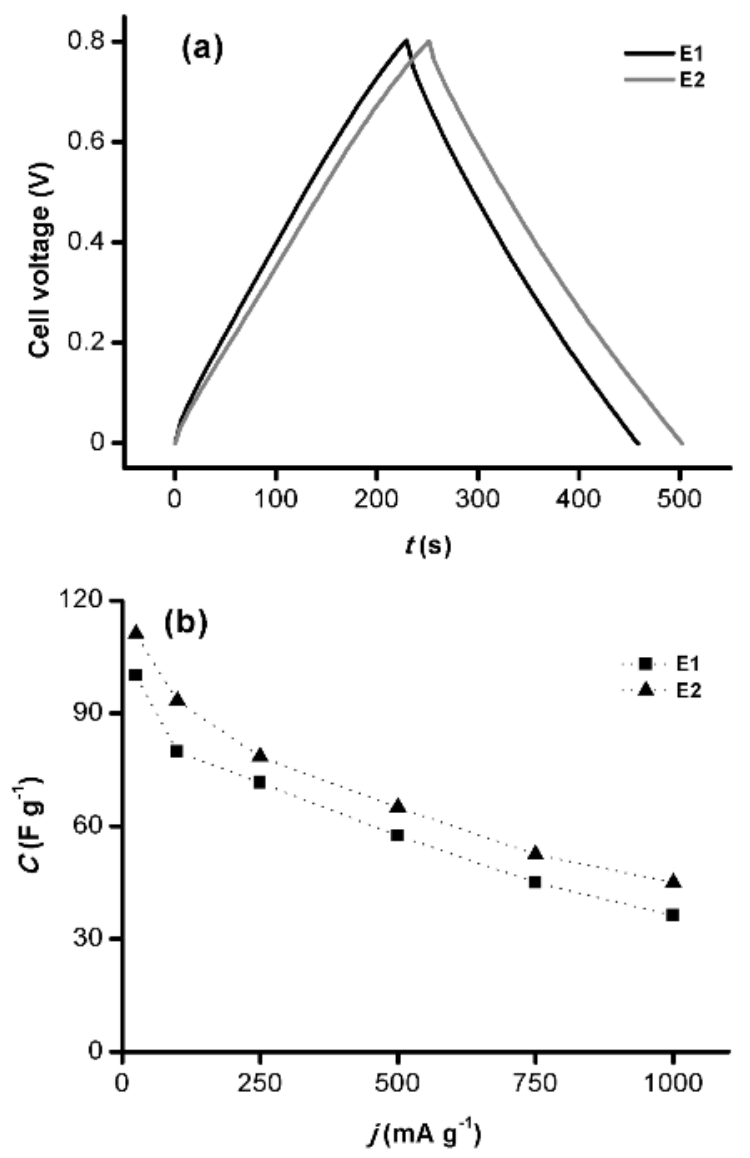

Figure 10: Electrochemical characterization using a two-electrode cell in $0.5 \mathrm{M} \mathrm{H}_{2} \mathrm{SO}_{4}$. Galvanostatic curves at a current density of $250 \mathrm{~mA} \mathrm{~g}^{-1}$ (a). Specific capacitance variation with increase of current density (b). 


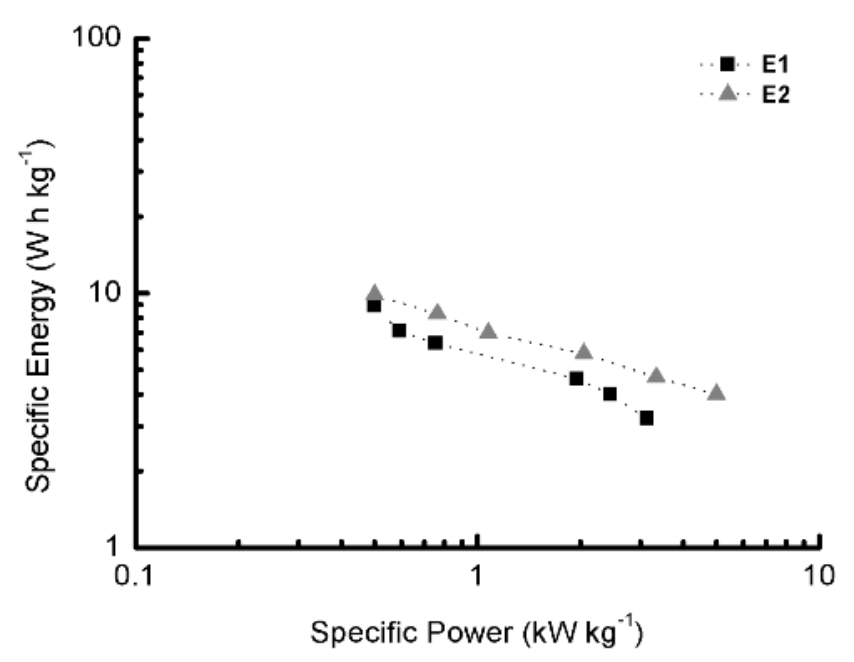

Figure 11: Ragone plot related to energy and power densities of samples E1 and E2 at a voltage window of $0.8 \mathrm{~V}(0-0.8 \mathrm{~V})$.

\section{Conclusions}

In this study it has been shown how the HTC process allows exploiting a lowvalue by-product/waste of the bioethanol industry as a carbon precursor. Such feedstock can be used without any further pretreatment, therefore requiring a minimal increase in process complexity and contributing largely towards its intensification. The HTC carbons obtained from the corncob and spruce hydrolysis products have been demonstrated to exhibit comparable morphology and chemical nature as those obtained from pure monosaccharides (e.g., glucose). As a consequence, their use could be easily extended to the synthesis of nanostructured carbon materials, which have so far been synthesized from glucose through HTC adopting either hard/soft templating strategies or adding structure-directing agents. As a proof of concept, in this work the synthesis of carbon hollow spheres has been successfully demonstrated by using silica-nanoparticle templates.

To introduce porosity in the synthesized HTC carbons, KOH chemical activation has also been successfully exploited. It has been shown that the produced ACs exhibit an extremely high porosity (pore volume $\sim 1.0 \mathrm{~cm}^{3} \mathrm{~g}^{-1}$ ) mostly composed of micropores ( $90 \%$ of total pore volume). Because of their favourable textural properties, these materials have further been tested as electrodes for supercapacitors yielding very promising results $\left(300 \mathrm{~F} \mathrm{~g}^{-1}\right.$ at $250 \mathrm{~mA} \mathrm{~g}^{-1}$ ). Such performances could be further 
improved by tailoring the AC properties (e.g., PSD, heteroatom content) during the synthesis step (i.e., controlling the activation-step variables).

Overall, the present work provides a remarkable contribution towards the implementation of the HTC process within industrial biorefinery schemes, as it shows how a readily available, high quantity, and low-value waste, generated during bioethanol production, can be effectively exploited as a precursor of HTC carbon materials, for which numerous applications have been reported within the available literature.

\section{Experimental Procedure}

\section{HTC carbon derived AC synthesis}

Spruce and corncob hydrolysis products were produced at the cellulosic ethanol demonstration plant in Örnsköldsvik (Sweden) operated by SEKAB E-Technology. The composition of analysis was carried out by SEKAB E-technology by means of HPLC. Both hydrolysis products samples were HTC-treated at $200^{\circ} \mathrm{C}$ for $24 \mathrm{~h}$ in a sealed autoclave equipped with a Teflon inlet.

After HTC treatment, the samples were filtered and washed with plenty of distilled water and then dried overnight in a vacuum oven at $80^{\circ} \mathrm{C}$. Chemical activation of both HTC carbons was then performed in a horizontal tubular oven using $\mathrm{KOH}$ as activating agent (Table 4). The ACs were thoroughly washed with $1 \mathrm{M} \mathrm{HCl}$ solution followed by a final distilled water wash.

Table 4: KOH activation parameters.

$\begin{array}{cc}\text { Temperature } & 700{ }^{\circ} \mathrm{C} \\ \text { Heating rate } & 3{ }^{\circ} \mathrm{C} / \mathrm{min} \\ \text { Holding time } & 1 \mathrm{~h} \\ \mathrm{KOH} \text { : Carbon precursor ratio } & 4: 1 \\ \text { Mixing } & \text { Physical }\end{array}$

\section{Synthesis of HTC carbon hollow spheres}

Typically, $10 \mathrm{~mL}$ aqueous solutions containing amino-functionalized silica nanoparticles (Amino-NPs, $120 \mathrm{mg}$ ) and carbohydrate-equivalent hydrolysis products $(0.3 \mathrm{mg})$ were prepared. After vigorous stirring for a few minutes, the solutions were then added in a glass inlet (30 mL volume) sealed in a Teflon-lined autoclave ( $45 \mathrm{~mL}$ volume) and placed in a laboratory oven preheated to the desired temperature (e.g., $180^{\circ} \mathrm{C}$ ) and left for the 
desired reaction time (e.g., 20 h). The powders obtained were then removed from the glass inlets and successively centrifuged and washed a few times in water and absolute ethanol to remove the residual unreacted precursors and by-products. The carbon-coated silica-based nano particles were then placed in a ceramic crucible in a carbonization oven and heated to the desired temperature (e.g., $950^{\circ} \mathrm{C}$ ) under an inert atmosphere (i.e., $\mathrm{N}_{2}$ at a flow rate of $10 \mathrm{~mL} \mathrm{~min}^{-1}$ ). The following heating program was used: a first ramp to reach $350^{\circ} \mathrm{C}$ at a speed of $5^{\circ} \mathrm{C} \min ^{-1}$, a second ramp to reach $950{ }^{\circ} \mathrm{C}$ at $2^{\circ} \mathrm{C} \min ^{-1}$ and an isothermal step of $2 \mathrm{~h}$. Samples were then allowed to cool to ambient conditions, removed from the oven, and washed twice overnight in a solution of ammonium hydrogen difluoride (4 mol\%) to remove the silica template. The as-synthesized hollow spheres were then washed in distilled water and dried overnight.

\section{Characterization of HTC carbons}

Elemental Analysis (EA) was performed using an Elementar vario MICRO cube. SEM images were acquired on a LEO 1550/LEO GmbH Oberkochen equipped with an Everhard Thornley secondary electron and in-lens detectors. Fourier transform infrared (FTIR) spectra of the materials were recorded in ATR geometry on a Varian 1000 FTIR spectrometer, Scimitar Series (FTS1000). ${ }^{13} \mathrm{C}$ solid-state MAS NMR spectra were acquired on a Bruker Avance $300 \mathrm{MHz}(7 \mathrm{~T})$ spectrometer using respectively $4 \mathrm{~mm}$ zirconia rotors as sample holders, spinning at MAS rate $\mathrm{n}_{\mathrm{MAS}}=14 \mathrm{kHz}$. The chemical shift reference was tetramethylsilane (TMS; $\mathrm{d}=0 \mathrm{ppm}$ ). ${ }^{1} \mathrm{H} \mathrm{t}_{1}$ relaxation time was set to 3 s. Proton-to-carbon CP MAS was used to enhance carbon sensitivity with a crosspolarisation time equal to $1 \mathrm{~ms}$.

\section{Porosity characterization}

The characterization of the porous texture was assessed by performing gas adsorption experiments, $\mathrm{N}_{2}(77 \mathrm{~K})$ and $\mathrm{CO}_{2}(273 \mathrm{~K})$ adsorption, in a QUADRASORB SI apparatus equipped with an automated surface-area and pore-size analyzer. The specific surface area and the micropore volume were calculated by fitting nitrogen adsorption data to BET and DR equation, respectively. ${ }^{[49]}$ Narrow micropore volume (mean pore size lower than about $0.7 \mathrm{~nm}$ ) was obtained by fitting DR equation to $\mathrm{CO}_{2}$ isotherm data. PSDs were 
evaluated from both adsorptive by using the quenched solid-state density functional theory (QSDFT) method for $\mathrm{N}_{2}$ and the non-local density functional theory (NLDFT) method for $\mathrm{CO}_{2}$ (QUADRAWIN software). TEM was carried out by using a Carl Zeiss Omega $912 \mathrm{X}$ at an acceleration voltage of $120 \mathrm{kV}$.

\section{Electrochemical experiments}

Suprapure sulfuric acid was from Merck, acetylene black was from Strem Chemicals and binder (polytetrafluoroethylene-PTFE) from Sigma Aldrich. The electrolyte solution was prepared with purified water obtained from an Elga Labwater Purelab system (18.2 $\mathrm{M} \Omega \mathrm{cm})$.

For the electrode preparation, the carbon materials were mixed with the binder polytetrafluoroethylene (PTFE, 60 wt. \%) and acetylene black (Strem Chemicals) in a ratio 80:10:10 wt. \%. The materials were mixed and pressed up to 1 ton for $10 \mathrm{~min}$. The total electrode weight (HTC carbon, binder, and acetylene black) used for the measurements in the three-electrode cell was about $40 \mathrm{mg}$. After that, the electrode was placed on a stainless steel mesh $(1 \mathrm{~cm}$ width and $6 \mathrm{~cm}$ height), which was used as current collector, by pressing the electrode onto the mesh under 1 ton for $10 \mathrm{~min}$.

The electrochemical characterization of the electrodes was performed by using a standard three-electrode cell configuration. The counter-electrode was a platinum wire, and a reversible hydrogen electrode (RHE) served as reference. All potentials mentioned in this work are referred to this electrode. An inert nitrogen atmosphere was maintained over the electrolyte. $0.5 \mathrm{M} \mathrm{H}_{2} \mathrm{SO}_{4}$ solution was used as aqueous electrolyte. The measurements were carried out with an EG\&G Potentiostat/Galvanostat model 273 and an Autolab PGSTAT302. The electrochemical behaviour of the samples was assessed by cyclic voltammetry at $1 \mathrm{mV} \mathrm{s}^{-1}$ and galvanostatic charge/discharge method. Capacitances were calculated from the scanning range between 0 and $0.8 \mathrm{~V}$ by dividing the imposed current with the slope of the linear chronopotentiograms plot, taking the average value between charge and discharge processes. The capacitance is expressed in $\mathrm{F} \mathrm{g}^{-1}$ taking into account the weight of the active part of the electrode.

Experiments were also performed in a two-electrode cell using a sandwich-type construction (electrode/separator/electrode) with a nylon membrane $(0.45 \mu \mathrm{m}$ pore size $)$ 
between the electrodes. Gold was used as the current collector and a $0.5 \mathrm{M} \mathrm{H}_{2} \mathrm{SO}_{4}$ solution as the electrolyte. Electrode discs with $10 \mathrm{~mm}$ diameter and about $0.25 \mu \mathrm{m}$ thickness were cut from carbon pastes. The values of specific capacitances of the twoelectrode cell were determined by galvanostatic charge-discharge measurements at different current densities and $\mathrm{CV}$ at $1 \mathrm{mVs}_{-1}$. ESR was calculated from the voltage drop $(\Delta \mathrm{V})$ observed in the discharge curve according to $\Delta \mathrm{V}=\mathrm{I} \cdot \mathrm{ESR}$.

\section{Acknowledgements}

The authors would like to thank SEKAB for making the hydrolysis product samples available and, therefore, for allowing the development of the work presented within this manuscript. The technical staff of the Colloids department at the Max Planck Institute of Colloids and Interfaces is thanked for all the help provided with analytical measurements. The Laboratoire de Chimie de la Matiere Condensee de Paris Centre 'and especially Dr. Niki Baccile, Prof. Florence Babonneau, and Ing. Guillaume Laurent are thanked for their help and assistance during NMR measurements. C.F. thanks Dr. Luca Bertinetti for the help provided with high-resolution SEM measurements. Financial support by the Ministerio de Ciencia e Innovación (MAT2010-15273 and CTQ200910813) and Generalitat Valenciana and FEDER (PROMETEO/2009/047 and ACOMP2012/133) projects are gratefully acknowledged. J.M.S. thanks Ministerio de Educación (SB2010-132).

\section{References}

[1] G. W. Huber, S. Iborra, A. Corma, Chem. Rev. 2006, 106, 4044.

[2] J. N. Chheda, G. W. Huber, J. A. Dumesic, Angew. Chem. 2007, 119, 7298; Angew. Chem. Int. Ed. 2007, 46, 7164.

[3] R. Palkovits, Angew. Chem. 2010, 122, 4434; Angew. Chem. Int. Ed. 2010, 49, 4336. [4] M. Stçcker, Angew. Chem. 2008, 120, 9340; Angew. Chem. Int. Ed. 2008, 47, 9200.

[5] A. A. Peterson, F. Vogel, R. P. Lachance, M. Froling, M. J. Antal, J. W. Tester, Energy Environ. Sci. 2008, 1, 32.

[6] K. Tajvidi, K. Pupovac, M. Kukrek, R. Palkovits, ChemSusChem 2012, 5, 2139 2142.

[7] P. Kumar, D. M. Barrett, M. J. Delwiche, P. Stroeve, Ind. Eng. Chem. Res. 2009, 48, 3713.

[8] J. C. Serrano-Ruiz, J. A. Dumesic, Energy Environ. Sci. 2011, 4, 83-99.

[9] B. Yang, C. E. Wyman, Biofuels Bioprod. Biorefin. 2008, 2, 26.

[10] A. T. W. M. Hendriks, G. Zeeman, Bioresour. Technol. 2009, 100, 10.

[11] M. W. Lau, C. Gunawan, B. E. Dale, Biotechnol. Biofuels 2009, 2, 30.

[12] N. Kuzhiyil, D. Dalluge, X. Bai, K. Ho Kim, R. C. Brown, ChemSusChem 2012, 5, 2228.

[13] J. H. Lora, W. G. Glasser, J. Polym. Environ. 2002, 10, 39.

[14] W. Thielemans, E. Can, S. S. Morye, R. P. Wool, J. Appl. Polym. Sci. 2002, 83, 323. 
[15] Suhas, P. J. M. Carrott, M. M. L. R. Carrott, Bioresour. Technol. 2007, 98, 2301.

[16] J. Hayashi, A. Kazehaya, K. Muroyama, A. O. Watkinson, Carbon 2000, 38, 1873.

[17] R. Xing, A. V. Subrahmanyam, H. Olcay, W. Oi, G. P. van Walsum, H. Pendse, G.

W. Huber, Green Chem. 2010, 12, 1933.

[18] R. Xing, W. Oi, G. W. Huber, Energy Environ. Sci. 2011, 4, 2193.

[19] S. Walton, A. van Heiningen, P. van Walsum, Bioresour. Technol. 2010, 101, 1935.

[20] L. O. Ingram, H. C. Aldrich, A. C. C. Borges, T. B. Causey, A. Martinez, F.

Morales, A. Saleh, S. A. Underwood, L. P. Yomano, S. W. York, J. Zaldivar, S. D. Zhou, Biotechnol. Prog. 1999, 15, 855.

[21] J. R. M. Almeida, D. Runquist, V. S. I. Nogue, G. Liden, M. F. Gorwa-Grauslund, Biotechnol. J. 2011, 6, 286.

[22] M. M. Titirici, M. Antonietti, Chem. Soc. Rev. 2010, 39, 103.

[23] B. Hu, K. Wang, L. Wu, S.-H. Yu, M. Antonietti, M.-M. Titirici, Adv. Mater. 2010, 22,813 .

[24] M. Antonietti, M. M. Titirici, C. R. Chim. 2010, 13, 167.

[25] R. J. White, N. Yoshizawa, M. Antonietti, M. M. Titirici, Green. Chem. 2011, DOI: $10.1039 / \mathrm{c} 1 \mathrm{gc} 15349 \mathrm{~h}$.

[26] M. Sevilla, A. B. Fuertes, Energy Environ. Sci. 2011, 4, 1765.

[27] M. Sevilla, A. B. Fuertes, R. Mokaya, Energy Environ. Sci. 2011, 4, 1400.

[28] K. Tang, L. Fu, R. J. White, L. Yu, M. M. Titirici, M. Antonietti, J. Maier, Adv. Energy Mater. 2012, 2, $873-877$.

[29] K. Tang, R. J. White, X. Mu, M. M. Titirici, P. A. van Aken, J. Maier, ChemSusChem 2012, 5, 400- 403.

[30] X. Lai, J. E. Halpert, D. Wang, Energy Environ. Sci. 2012, 5, 5604.

[31] M. M. Titirici, M. Antonietti, N. Baccile, Green Chem. 2008, 10, 1204 - 1212.

[32] A. Gandini, M. N. Belgacem, Prog. Polym. Sci. 1997, 22, 1203 - 1379.

[33] M. Mçller, P. Nilges, F. Harnisch, U. Schrçder, ChemSusChem 2011, 4, 566- 579.

[34] N. S. Mosier, C. M. Ladisch, M. R. Ladisch, Biotechnol. Bioeng. 2002, 79, 610 618.

[35] N. Baccile, G. Laurent, F. Babonneau, F. Fayon, M.-M. Titirici, M. Antonietti, J. Phys. Chem. C 2009, 113, $9644-9654$.

[36] C. Falco, F. Perez Caballero, F. Babonneau, C. Gervais, G. Laurent, M.-M. Titirici, N. Baccile, Langmuir 2011, 27, $14460-14471$.

[37] C. Falco, N. Baccile, M.-M. Titirici, Green Chem. 2011, 13, 3273 -3281.

[38] M. A. Lillo-Rdenas, J. Juan-Juan, D. Cazorla-Amoros, A. Linares-Solano, Carbon 2004, 42, 1371.

[39] M. Sevilla, C. Falco, M. M. Titirici, A. B. Fuertes, RSC Adv. 2012, 2, 12792 12797.

[40] S. Bose, T. Kuila, A. K. Mishra, R. Rajasekar, N. H. Kim, J. K. Lee, J. Mater. Chem. 2012, 22, 767-784.

[41] E. Frackowiak, F. Bguin, Carbon 2001, 39, 937-950.

[42] L. Zhao, N. Baccile, S. Gross, Y. Zhang, W. Wei, Y. Sun, M. Antonietti, M. M. Titirici, Carbon 2010, 48, 3778 - 3787.

[43] M. Inagaki, H. Konno, O. Tanaike, J. Power Sources 2010, 195, 7880 -7903.

[44] A. G. Pandolfo, A. F. Hollenkamp, J. Power Sources 2006, 157, 11 -27. 
[45] M. J. Bleda-Martínez, J. A. Maciá-Agulló, D. Lozano-Castelló, E. Morallón, D. Cazorla-Amorós, A. Linares-Solano, Carbon 2005, 43, 2677 -2684.

[46] M. Kawaguchi, T. Yamanaka, Y. Hayashi, H. Oda, J. Electrochem. Soc. 2010, 157, A35-A40.

[47] O. Barbieri, M. Hahn, A. Herzog, R. Kçtz, Carbon 2005, 43, 1303- 1310.

[48] M. D. Stoller, R. S. Ruoff, Energy Environ. Sci. 2010, 3, $1294-1301$.

[49] D. Cazorla-Amorós, J. Alcaniz-Monge, M. A. Casa-Lillo, A. Linares Solano, Langmuir 1998, 14, 4589. 